Research Article

\title{
Deformation and Damping Characteristics of Lightweight Clay-EPS Soil under Cyclic Loading
}

\author{
Yundong Zhou, ${ }^{1}$ Mingdong Li $\mathbb{D},{ }^{2}$ Qibao He, ${ }^{1}$ and Kejun Wen $\mathbb{D}^{3}$ \\ ${ }^{1}$ Key Laboratory of Ministry of Education for Geomechanics and Embankment Engineering, Hohai University, \\ Nanjing 210098, China \\ ${ }^{2}$ School of Civil Engineering and Architecture, East China University of Technology, Nanchang 330013, China \\ ${ }^{3}$ Department of Civil and Environmental Engineering, Jackson State University, Jackson, MS 39217, USA
}

Correspondence should be addressed to Mingdong Li; 1md@ecit.edu.cn

Received 14 June 2018; Revised 23 August 2018; Accepted 13 September 2018; Published 10 October 2018

Guest Editor: Yongfeng Deng

Copyright (c) 2018 Yundong Zhou et al. This is an open access article distributed under the Creative Commons Attribution License, which permits unrestricted use, distribution, and reproduction in any medium, provided the original work is properly cited.

\begin{abstract}
Lightweight Clay-EPS Soil (LCES) is a newly developed material which has many merits such as the adjustability of strength and density, simplicity for construction, and economical efficiency. It has been widely applied in practical engineering, e.g., soft ground improvement, the solvent of bridge head jump, earthfill of pipeline, and broadening of highway. Meanwhile, construction castoff and industrial waste can be recycled as a major ingredient in LCES. The dynamic deformation characteristics of LCES and clay were comprehensively studied using laboratory dynamic triaxial tests. It was found that the compressive strain of LCES increased while the growth rate of strain decreased with the increasing number of cycles, which conformed to a hyperbola model. The dynamic secant elastic modulus of LCES decreased with the increase of dynamic strain, which was represented by strain softening. The dynamic modulus of clay decreased sharply, while that of LCES decreased marginally. Moreover, the damping ratio of LCES tended to increase with the increasing dynamic strain. The damping ratio of LCES was lower than that of clay at the same strain level. It was also found that cement content had a negative relationship with the damping ratio of LCES, while the effect of EPS beads content was adverse. The damping ratio of both LCES and clay decreased moderately.
\end{abstract}

\section{Introduction}

Public infrastructures, such as the highway, railway, and city subway, have confronted many challenges, including the bumping at the bridge-head in highway, undue settlement of soft foundation, unstable retaining wall, etc. The overweight of soil can be one of the major causes. Expanded polystyrene (EPS) composite soil is a type of artificial material that consists of soil, EPS bead, water, and cementing material (e.g., cement and fly ash) [1,2]. The EPS composite soil had been applied in many engineering constructions in Japan since the 1980s, and both the density and strength performance of EPS composite soil can achieve the engineering requirement $[3,4]$. Lightweight Clay-EPS Soil (LCES) is a kind of geotechnical material which has many merits such as the lightness, adjustability of strength and density, and fluidity. It has been widely applied in many engineering practice, including the treatments of soft foundation, vehicle jump at bridge head, backfill of pipelines, and broadening of highway, as shown in Figure 1. The waste soils generated from engineering constructions can be reused as the major ingredient in LCES by using the curing agent and lightweight filler. Recycling of the waste soils could significantly reduce the cost of engineering construction. Cement mixed with fly ash, lime, and waste gypsum were normally adopted as curing agent to improve the mechanical performance of LCES. Meanwhile, the household waste such as foam plastic and tire beads could be used as the lightweight filler. Moreover, the LCES was widely applied in many engineering projects in China, such as the road foundation reinforcement, slope stability, and construction backfill $[5,6]$.

There are many research achievements on lightweight soil, especially on its static characteristics. Dry density of LCES decreases dramatically with the increase of EPS beads 


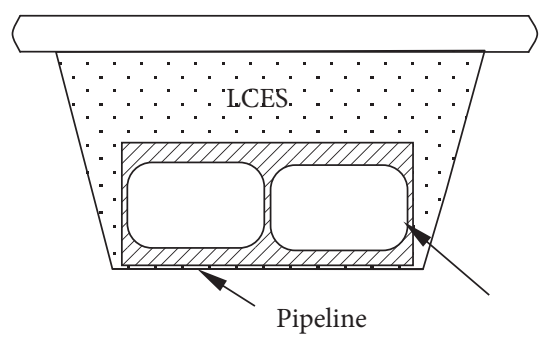

(a)

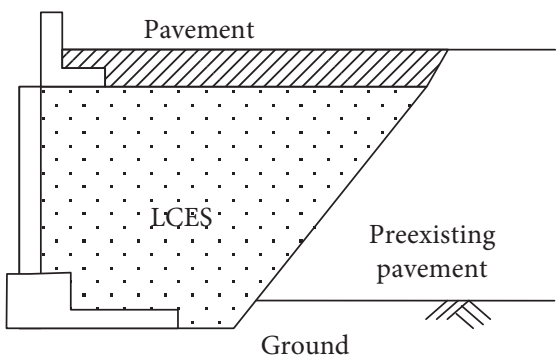

(c)

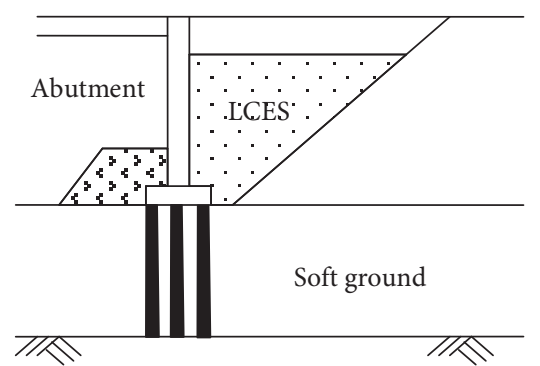

(b)

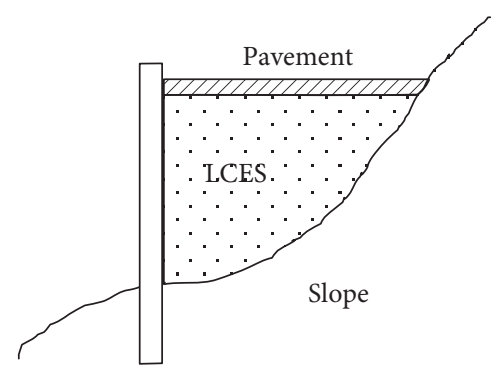

(d)

FIgURE 1: The engineering applications of LCES. (a) Pipeline backfill. (b) Solvent of bridge head jump. (c) Road widening. (d) Slope earthfill.

volumetric content, while it increases slightly with the increase of cement content. Unconfined compressive strength increases dramatically in a parabolic relationship with the increase of cement content, while decreases with the increase of EPS beads volumetric content in a hyperbolic relationship. Cohesion increases with the increase of cement content because it is mainly caused by the bonding function of hydration products of cement. Friction angle decreases with the increase of EPS beads volumetric content, which is caused by the smoother surfaces of EPS beads than sand grains. Quantitative relationships between physicomechanical properties of sand-EPS beads soil and material proportion were provided [7]. Cohesion decreases with the increase of the EPS size, which was theoretically proved. According to the fact that the strength reduction rate is far below the reduction rate of unit price, EPS beads with diameter of 3-5 mm can be used in construction [8]. A model for compaction density of sand-EPS beads soil was established based on material composition and the physical essence of soil compaction. It was verified by lab tests that the predicted value was close to the measured wet density with relative error between $0.282 \%$ and $5.267 \%$ under different compaction conditions [9]. The volume ratio of EPS beads to the soil, initial average effective consolidation pressure, initial consolidation stress ratio, initial intermediate principal stress coefficient, and initial principal stress direction angle had great effects on the maximum dynamic shear modulus and the reference shear strain $[10,11]$. The stress increased when LCES was considered as viscous elastic material instead of elastic material [12]. The shear stress attenuated more rapidly with the depth [13]. The damage caused by dynamic loading could be effectively reduced by LCES [14]. Data from stress-controlled cyclic uniaxial tests showed a logarithmic decrease in the damping ratio of EPS geofoam with the increasing axial strain amplitude. For cyclic axial strain amplitudes greater than 1.0\%, LCES exhibited a viscoelastoplastic behavior associated with the occurrence of permanent plastic strains at the end of the cyclic tests [15]. The simulation study on the process of falling rocks found that LCES could reduce the impact of falling rocks [16]. Gao et al. applied EPS composite soil as backfills and found that the dynamic deformation mode of EPS composite soil was different from that of fine sand [2].

To investigate the deformation and damping characteristics of LCES $t$, a series of cyclic triaxial tests on LCES with different proportions were carried out by using the multifunctional indoor triaxial apparatus. The dynamic deformation characteristics of LCES were obtained. The influences of cement content, EPS beads content, and confining pressure on the dynamic modulus and damping ratio of LCES were analyzed and compared with the dynamic deformation characteristics of clay.

\section{Materials and Methods}

2.1. Clay. The clay adopted in this study was collected from 6 meters below the ground surface of Olympic Sports Center, located in Hexi, Nanjing. The geotechnical properties of this clay are shown in Table 1 , and its particle size distribution is shown in Figure 2. The clay soil is classified as Lean Clay (CL) based on Unified Soil Classification System standard.

2.2. Cement. The binder used in the experiment was $32.5 \#$ Portland cement produced in Nanjing, China.

2.3. Expanded Polystyrene (EPS) Beads. EPS is a macromolecule polymer with prior lightweight properties. During the forming process of EPS beads, a large number of individual pores were formed because of expanding of blowing 
TABLE 1: Geotechnical properties of clay.

\begin{tabular}{lcccccccc}
\hline $\begin{array}{l}\text { Unit weight } \gamma \\
\left(\mathrm{kN} \cdot \mathrm{m}^{-3}\right)\end{array}$ & $\begin{array}{c}\text { Water } \\
\text { content } \omega(\%)\end{array}$ & $\begin{array}{c}\text { Void } \\
\text { ratio } e\end{array}$ & $\begin{array}{c}\text { Specific } \\
\text { gravity } G_{\mathrm{s}}\end{array}$ & $\begin{array}{c}\text { Degree of } \\
\text { saturation } \mathrm{Sr}(\%)\end{array}$ & $\begin{array}{c}\text { Plastic } \\
\text { imit } \omega_{\mathrm{P}}(\%)\end{array}$ & $\begin{array}{c}\text { Liquid } \\
\text { limit } \omega_{\mathrm{L}}(\%)\end{array}$ & $\begin{array}{c}\text { Plastic } \\
\text { index } I_{\mathrm{P}}\end{array}$ & $\begin{array}{c}\text { Liquid } \\
\text { index } I_{\mathrm{L}}\end{array}$ \\
\hline 16.4 & 62.3 & 1.70 & 2.73 & 100 & 27.3 & 47.5 & 20.2 & 1.73 \\
\hline
\end{tabular}

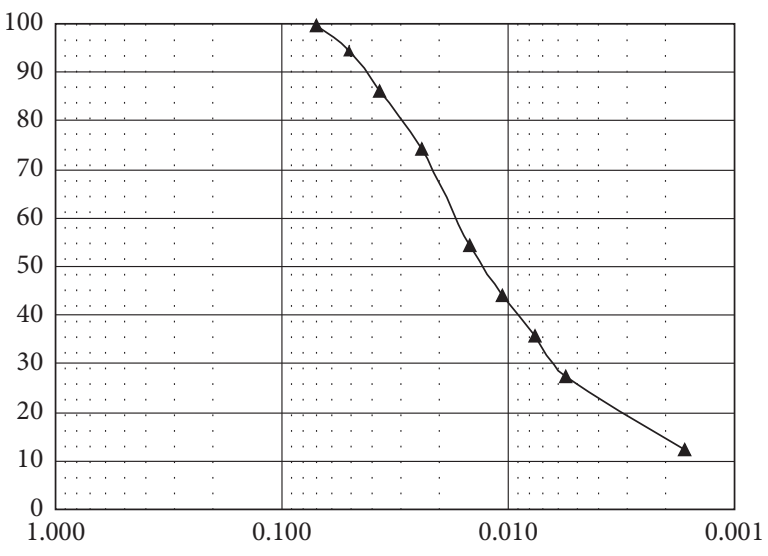

Figure 2: Particle size distribution of clay.

agent, resulting in the increase in volume by up to 40 times. The EPS Beads adopted in this study was provided by Nanjing Youbang Foamed Plastic Co. Ltd, with $0.023 \mathrm{~g} / \mathrm{cm}^{3}$ in density and $3 \mathrm{~mm}$ in average diameter.

2.4. Test Design. To investigate the effect of material proportion on the deformation and damping characteristics of LCES under cyclic loading, totally 9 dosages of LCES were selected in this study, as listed in Table 2. Different ratios of cement and EPS beads were added to clay soil to prepare LCES with different material proportions. Four specimens were prepared for each dosage of additive. The value of $\alpha$ indicates the cement addition ratio by weight of dry soil, while $\beta$ means the EPS addition ratio by weight of dry soil.

2.5. Preparation of Specimens. The materials were prepared and weighed before being mixed thoroughly with a blender at $100 \mathrm{rot} / \mathrm{min}$. The mixtures were then put into the mold and compacted through 5 layers. The specimen was $61.8 \mathrm{~mm}$ in diameter and $140 \mathrm{~mm}$ in height. The specimens were cured in a curing box at $20 \pm 2{ }^{\circ} \mathrm{C}$ and $99 \%$ humanity continuously for $27 \mathrm{~d}$. The cross sections of T11, T12, and T13 are shown in Figure 3. The specimens were placed in air extractor, and vacuumized for $20 \mathrm{~min}$ at a vacuum degree of $-0.1 \mathrm{MPa}$. Finally, the specimens were fully saturated through opening the water inlet valve. The saturated specimens were set in water environment for another 24 hours before the dynamic triaxial test.

2.6. Test Methods. The specimens were tested by a multifunctional automatic dynamic triaxial apparatus which was developed by Hohai University and Japan Round Well Co., LTD. The dynamic triaxial test of LCES was conducted in accordance with the dynamic triaxial method in
TABle 2: Proportions of cement and EPS.

\begin{tabular}{lcc}
\hline Maker & $\alpha(\%)$ & $\beta(\%)$ \\
\hline T11 & 5 & 2 \\
T12 & 5 & 3 \\
T13 & 5 & 4 \\
T21 & 10 & 2 \\
T22 & 10 & 3 \\
T23 & 10 & 4 \\
T31 & 20 & 2 \\
T32 & 20 & 3 \\
T33 & 30 & 4 \\
T00* & 0 & 0 \\
\hline
\end{tabular}

${ }^{*}$ T00 is the control test with material clay.

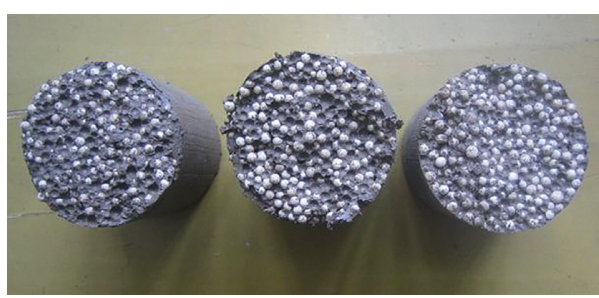

Figure 3: Cross sections of T11, T12, and T13.

geotechnical test procedures. The specimens removed from water were placed in a triaxial cell which connects with vibration equipment. A cell pressure $(20 \mathrm{kPa})$ was applied to saturate the pipe line around $30 \mathrm{~min}$ until there was no air bubble in the drainage pipe. The back pressure $(100 \mathrm{kPa})$ was then applied to fully saturate the specimens. Certain confining pressures $(30 \mathrm{kPa}, 60 \mathrm{kPa}$, and $90 \mathrm{kPa})$ were applied to the specimen for consolidation. The consolidation process was finished when the volume change of the specimen had been less than $0.1 \mathrm{~mL}$ in $5 \mathrm{~min}$. After consolidation, undrained shear tests were conducted until dynamic strain exceeds $5 \%$.

The dynamic load applied in this test was in the form of sine wave with a frequency of $0.1 \mathrm{~Hz}$. The amplitude was controlled by the dynamic shear stress ratio $(s)$, as shown in Equation (1). The dynamic shear stress ratio of LCES was applied, and 10 cycles was loaded.

$$
s=\frac{\tau_{\mathrm{d}}}{\sigma_{\mathrm{c}}}=\frac{\sigma_{\mathrm{d}}}{2 \sigma_{\mathrm{c}}}=0.5
$$

where $s$ is the dynamic shear stress ratio, i.e., the ratio of shear stress with respect to confining stress in the $45^{\circ}$ surface of the specimen; $\tau_{\mathrm{d}}$ is the dynamic shear stress amplitude in the $45^{\circ}$ surface of the specimen; $\sigma_{c}$ is the consolidation confining pressure; and $\sigma_{\mathrm{d}}$ is the amplitude of axial dynamic load. 


\section{Results and Discussion}

3.1. Time History Character Curve of Strain of LCES. The dynamic strain versus time curve is shown in Figure 4 . When dynamic shear stress was 0.5 , the strain of LCES was mainly compressive strain compared with clay soil. The strain scope of LCES was affected by the cement content. When the cement content was $5 \%$, the strain scope is around $6-7 \%$. However, the strain scope reduced to $4 \%$ as the cement content reached $15 \%$. This might be caused by the strong cementation force of cement, which improved LCES' ability to resist stress.

The relationship between the dynamic strain of LCES and the number of load cycles is presented in Figure 5. The compression strain of LCES tended to increase with the increase of load cycles. This might be caused by the reduction of void space and volume shrinkage of EPS beads under compression stress. In addition, it was found that the growth rate of strain decreased with the increase of cycle numbers, but the dynamic strain leveled off. This finding indicated that the strength of the dynamic load was lower than the critical dynamic strength, when the dynamic shear stress ratio of LCES was 0.5 . In this case, there were no or minor damages of soil structure, and the soil structure did not enter the stage of shear vibration and vibration failure. Soil deformation was mainly caused by the vibration and compaction of soil beads which was caused by vertical displacement. Yan et al. found a different trend on clay soil that $\varepsilon_{\mathrm{d}}$ initially increased slowly with $N$, followed by a more rapid increase [17].

3.2. Dynamic Secant Elastic Modulus of LCES. The hysteresis curve of LCES under cyclic loading is shown in Figure 6. The curve moved from point $\mathrm{O}$ along arc $\mathrm{OA}$ to point $\mathrm{A}$ with the increase of stress during the loading process. However, the curve moved from point $\mathrm{A}$ along the arc $\mathrm{ABC}$ to point $\mathrm{B}$ during the unloading process. Meanwhile, point $B$ moved along arc BCD to point $\mathrm{D}$ in the process of reverse loading and unloading, and point $\mathrm{D}$ did not coincide with point $\mathrm{O}$, which indicated that the deformation of LCES under dynamic load included elastic deformation and plastic deformation. The $\Delta \varepsilon_{\mathrm{d}}$ presented in Figure 6 is the plastic deformation after 7 days of loading. A uniform plastic deformation $\Delta \varepsilon_{\mathrm{d}}$ was assumed since the plastic deformation ran through the whole loading process. The plastic deformation was uniformly distributed to all the points on the curve, and the corrected hysteresis loop was obtained by subtracting the amount of evenly distributed plastic deformation from the collected deformation, as shown by the dash line in Figure 6. The corrected hysteresis loop was occlusive, and it was the same as that of ordinary soil. For clay soil, the slope of the line from the point of origin to the point of the hysteresis loop was taken as the equivalent dynamic modulus of elasticity. It was not appropriate to apply the equivalent dynamic elastic modulus to LCES since the cumulative deformation of LCES was large and the hysteresis loop deviated too much from the origin. Therefore, the dynamic secant elastic modulus $E_{\mathrm{sec}}$ was adopted for analysis as shown in Figure 7. The slope of the vertex connection line of the hysteresis loop corresponding to various loads was the same as the equivalent dynamic elastic modulus of clay.

The curves of $E_{\mathrm{sec}} \sim \varepsilon_{\mathrm{d}}$ under different confining pressures are shown in Figure 8. In general, the dynamic secant elastic modulus of LCES decreased with the increase of dynamic strain, which was represented by strain softening and exhibited a good hyperbolic relationship. The main reason was that the rigidity of LCES mainly came from cementing of cement hydrate. With the increase of the strain, the effect of cementing was gradually damaged and the rigidity of LCES was reduced. In the same proportion of LCES, the motioncutting line modulus increased with the increase of confining pressure. This might be explained by the fact that the greater confining pressure caused a denser specimen and achieved a higher stiffness. This finding is the same as the performance of conventional soil.

The curve of $E_{\mathrm{sec}} \sim \mathcal{E}_{\mathrm{d}}$ on different cement content is shown in Figure 9. In the same EPS beads content and confining pressure, the elastic modulus of the moving secant modulus of LCES gradually increased with the increase of cement content, which indicated that the addition of cement could improve the dynamic stiffness of LCES. Higher cement content achieves better cementation function of particles and more reduction of porosity ratio. The $E_{\mathrm{sec}}$ of LCES decreased slower with the increase of $\varepsilon_{\mathrm{d}}$ than that in ordinary clay. When the cement content increased, the $E_{\mathrm{sec}} \sim \mathcal{E}_{\mathrm{d}}$ curve approached a linear relationship which indicated that LCES had a better deformation resistance than ordinary clay under dynamic force. This can be attributed to the fact that cement hydrate cementation enhanced the deformation resistance under dynamic force after the soil and cement were completely mixed.

The curve of $E_{\mathrm{sec}} \sim \varepsilon_{\mathrm{d}}$ on different EPS beads content is shown in Figure 10. When cement content was $10 \%$, there was no remarkable difference in $E_{\mathrm{sec}}$ with the increase of EPS beads content, which indicated that the effect of the relative cement content and the EPS volumetric content on dynamic stiffness was negligible. This also indicated that $10 \%$ cement mixed clay and EPS beads had similar stiffness. Meanwhile, $E_{\text {sec }}$ decreased with the increase of EPS content when cement content increased to $15 \%$. It was illustrated that the cement cementation was enhanced under high cement content, and the stiffness of soil-cement was significantly greater than that of EPS beads. In this case, the content of cement relatively decreased due to the increase of EPS beads content, which resulted in the reduction of the overall motion-cutting line modulus.

3.3. Damping Ratio of LCES. The damping ratio, $D$, represented the viscous property of soil, which was an important index to measure the vibration damping property of soil and had a significant influence on the dynamic response of soil. $D$ in this study was defined as the ratio of the actual damping coefficient to the critical damping coefficient as shown in Equation (2), where $A_{\mathrm{L}}$ is the area of the hysteresis loop and $A_{\mathrm{T}}$ is the area of the shadow triangle as shown in Figure 11. 


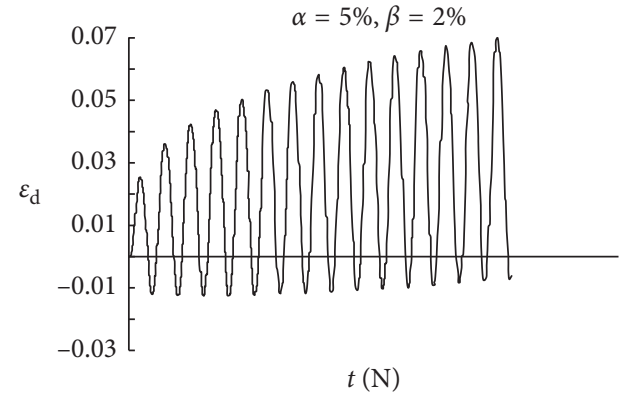

(a)

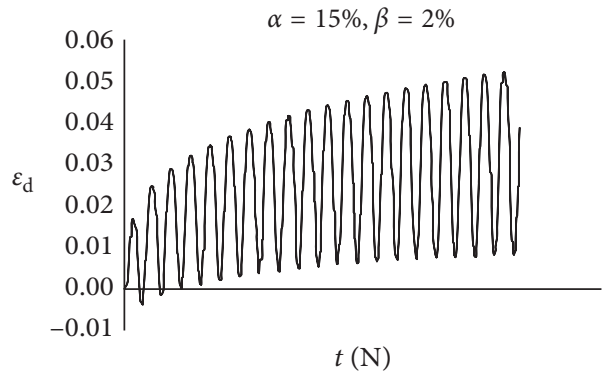

(c)

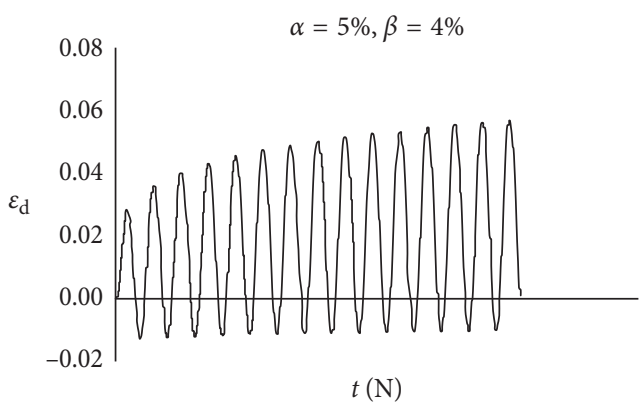

(b)

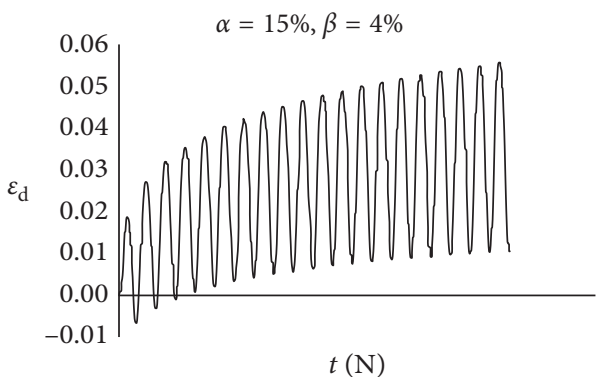

(d)

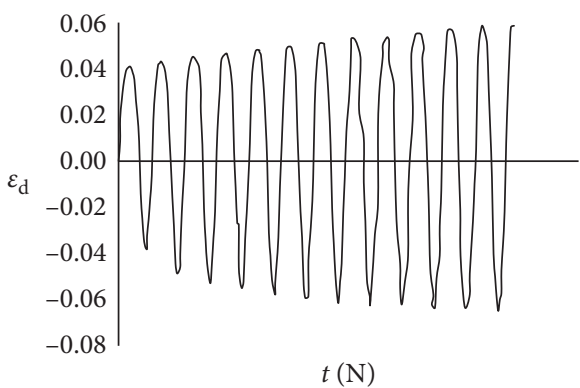

(e)

FIgURE 4: Typical dynamic strain time history character curves of LCES. (a) T11, (b) T13, (c) T31, (d) T33, and (e) T00 (material clay).

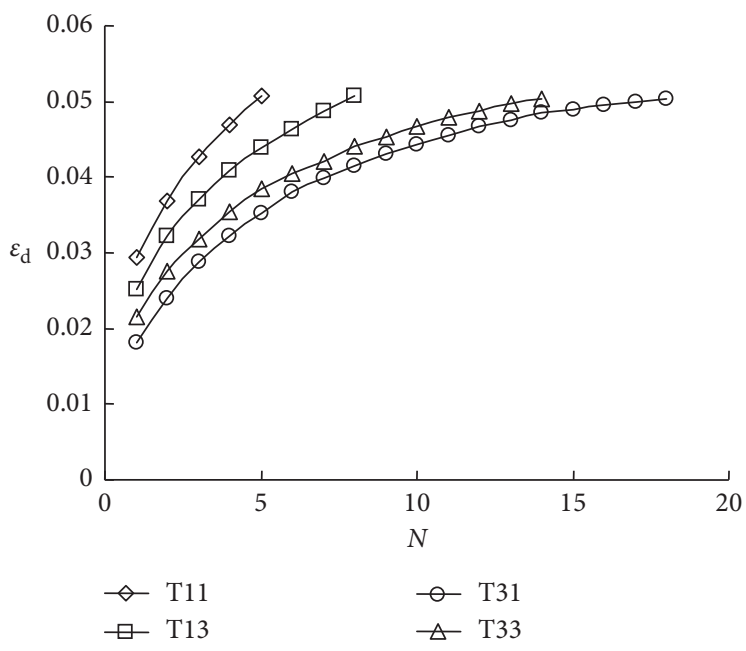

FIgURE 5: The dynamic strain behavior of LCES as a function of the number of load cycles. 


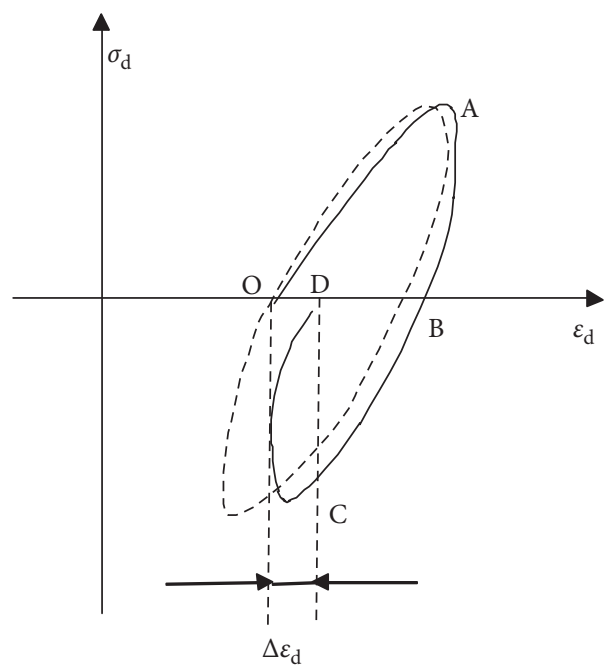

FIGURE 6: The hysteresis curve of LCES.

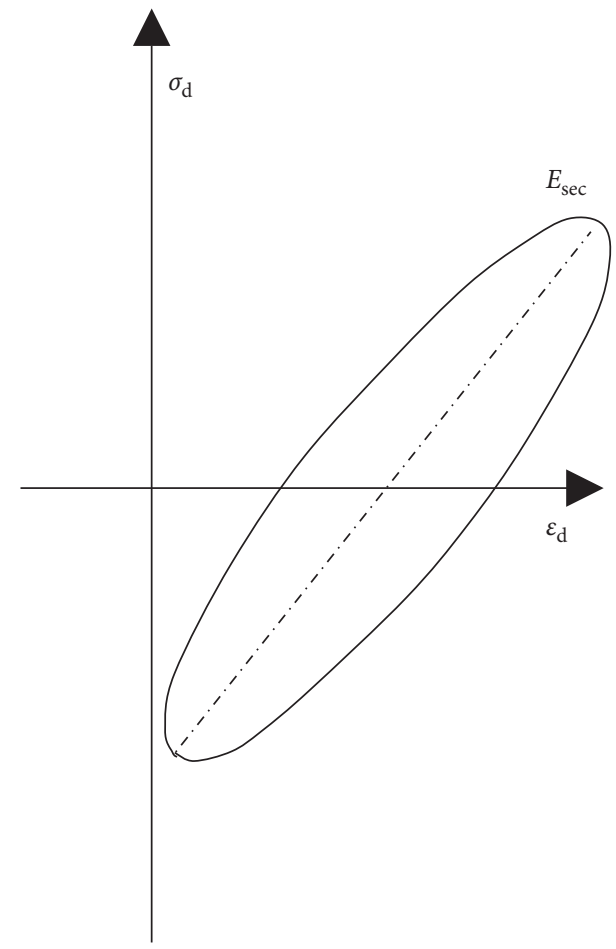

Figure 7: Dynamic secant elastic modulus $E_{\text {sec }}$.

$$
D=\frac{A_{\mathrm{L}}}{4 \pi A_{\mathrm{T}}} .
$$

Figure 12 presents the relationships between the damping ratio and dynamic strain of LCES and clay at different cement content. The damping ratio of LCES and clay increased gradually as the dynamic strain increased. Maher et al. also found similar results that the damping ratio of cement-treated sand was increased with the increase of shear strain [18]. Cement content had significant effects on the LCES damping ratio. The damping ratio of LCES was lower than that of clay, and it decreased with the increase of cement content which indicated that the damping ratio of LCES could be controlled by adjusting the cement content. This might be caused by that cement hydrate increased the stiffness of soil and reduced the viscosity of soil, which resulted in the decrease of the damping ratio.

Figure 13 presents the relationship between the damping ratio and dynamic strain of LCES and clay at different beads content. The damping ratio of LCES increased with the increase of EPS beads content, which indicated that EPS beads could absorb more vibration energy. This might be due to the fact that EPS beads were soft and nonlinear elastic. When EPS beads content increased, the cement content decreased correspondingly, which might weaken the effect of cement hydrate on the damping ratio of LCES. Gao et al. found that there was no significant different on the damping ratio with different EPS content when shear strain was less than $0.5 \%$ [19]. When shear strain exceeded $0.5 \%$, the larger the EPS beads content, the larger the damping ratio. They believed that larger EPS bead content generated more weak interfaces between EPS beads and cemented soil [19].

Figure 14 presents the relationship between the damping ratio and dynamic strain of LCES and clay under different confining pressures. The damping ratio of LCES and clay decreased slightly with the increase of the confining pressure in the range of $30 \mathrm{kPa}$ to $90 \mathrm{kPa}$.

\section{Conclusions}

For LCES with cement content between 5\% and 15\%, EPS beads content was between $2 \%$ and $4 \%$, confining pressure was between $30 \mathrm{kPa}$ and $90 \mathrm{kPa}$, and dynamic shear stress ratio was 0.5 , the following dynamic deformation characteristics were found:

(1) The compressive strain of LCES was significantly greater than the tensile strain. The tensile strain decreased with the increase of cement content. There was almost no tensile strain occurred when the cement content increased to $15 \%$. 


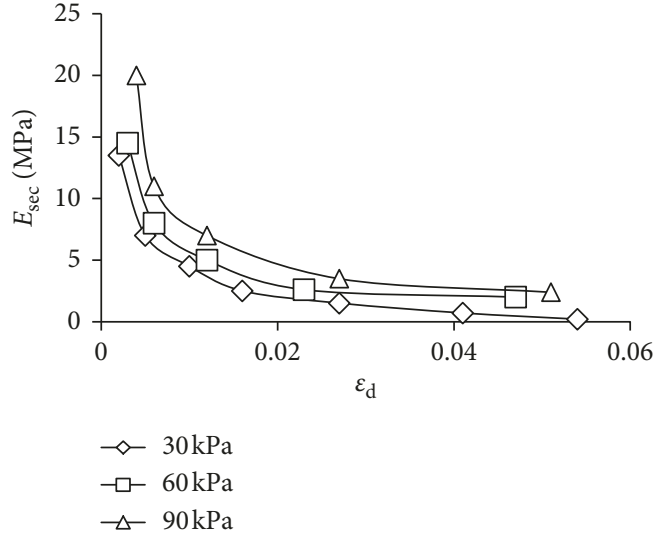

(a)

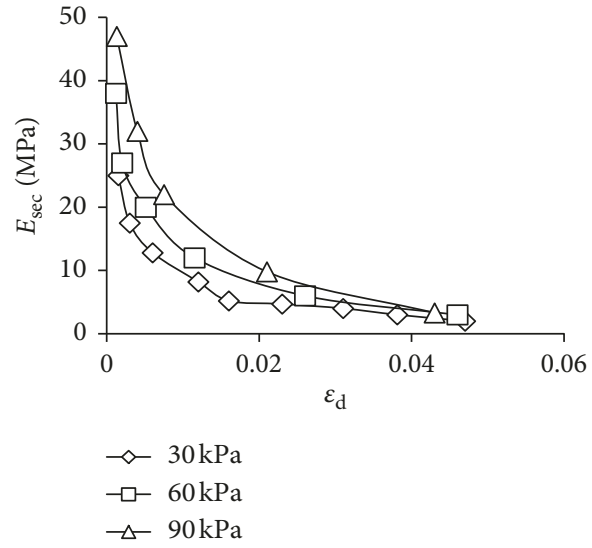

(b)

FIgURE 8: The curve of $E_{\mathrm{sec}} \sim \varepsilon_{\mathrm{d}}$ under different confining pressures. (a) T13; (b) T31.

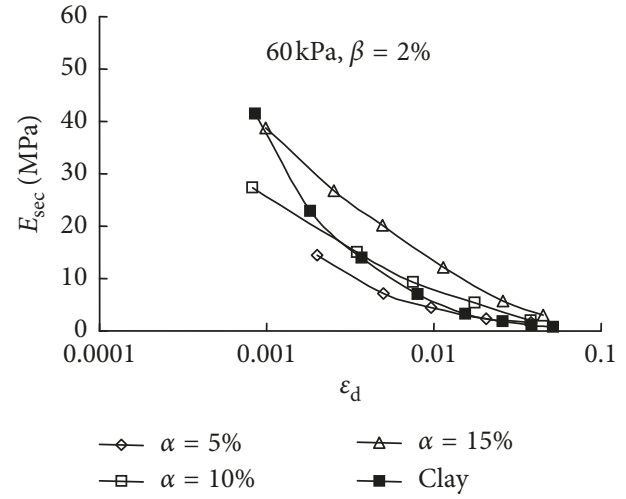

(a)

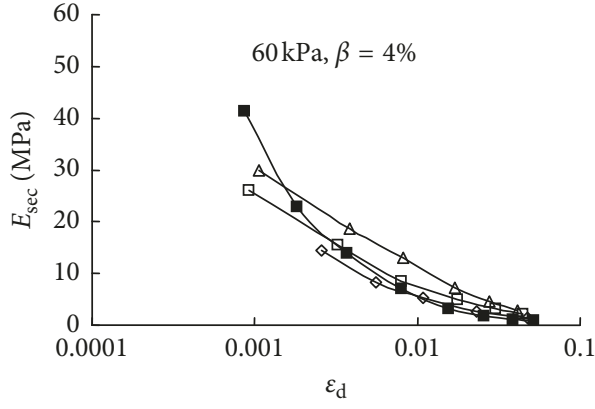

$\neg \alpha=5 \% \quad \triangle \alpha=15 \%$

$\square \alpha=10 \% \quad \rightarrow$ Clay

(b)

Figure 9: The curve of $E_{\mathrm{sec}} \sim \mathcal{E}_{\mathrm{d}}$ on different cement content.

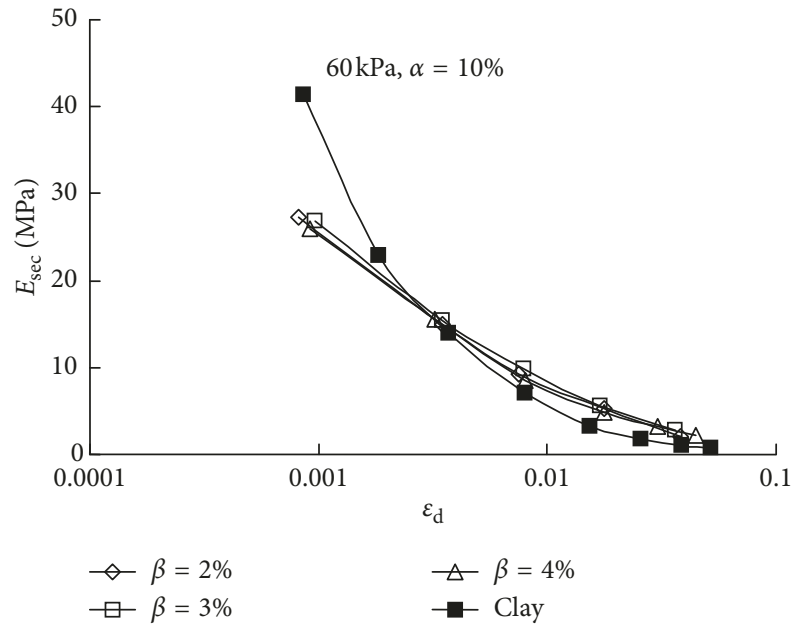

(a)

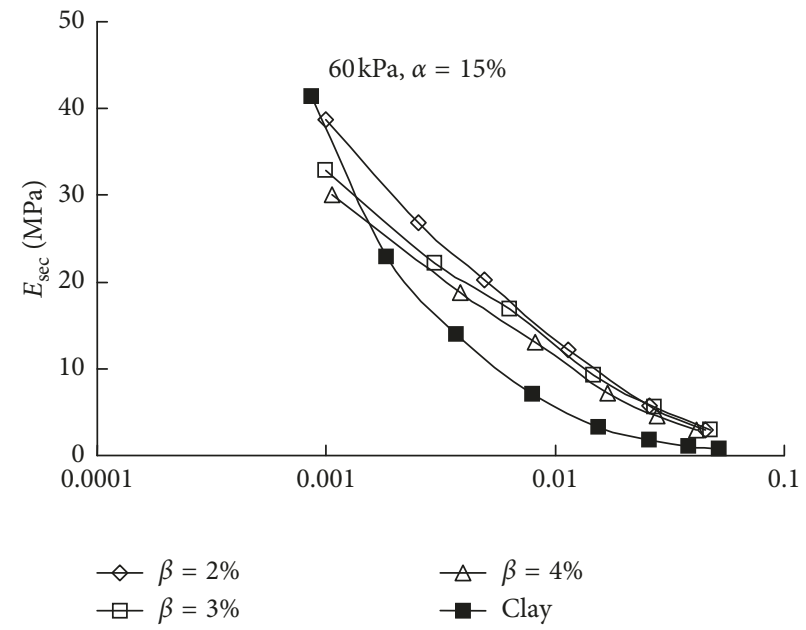

(b)

Figure 10: The curve of $E_{\mathrm{sec}} \sim \mathcal{E}_{\mathrm{d}}$ on different EPS beads content. 


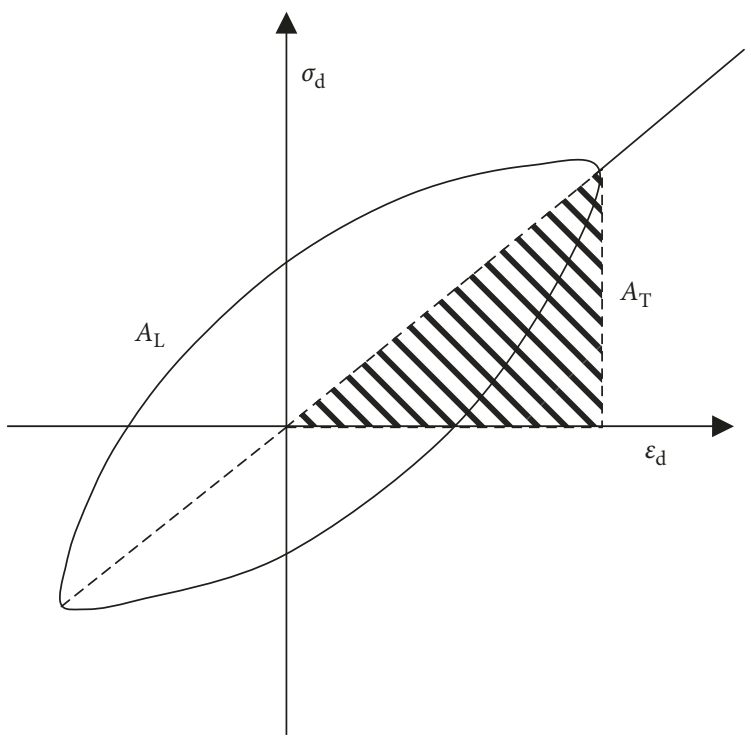

FIgURE 11: Definition of damping ratio.

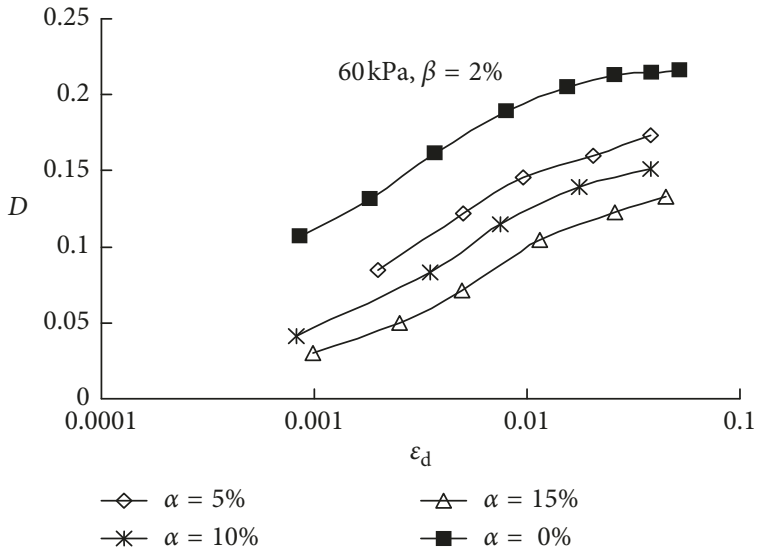

(a)

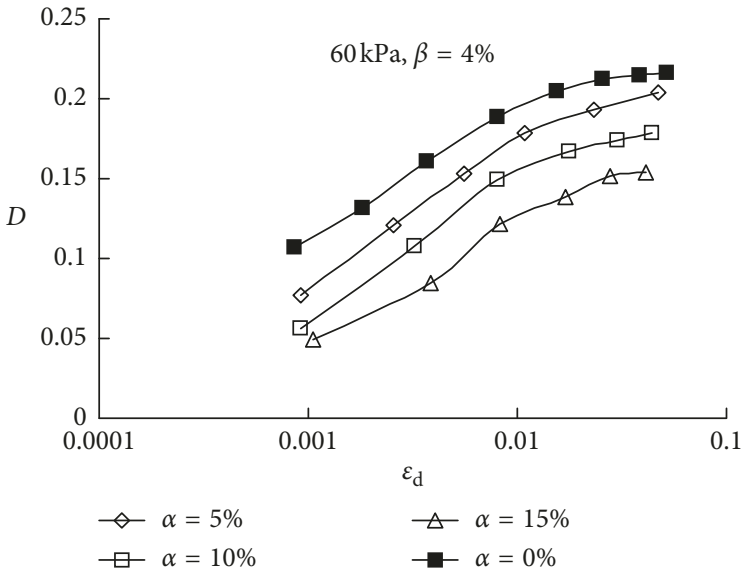

(b)

Figure 12: Relationship between the damping ratio and dynamic strain of LCES and clay at different cement content.

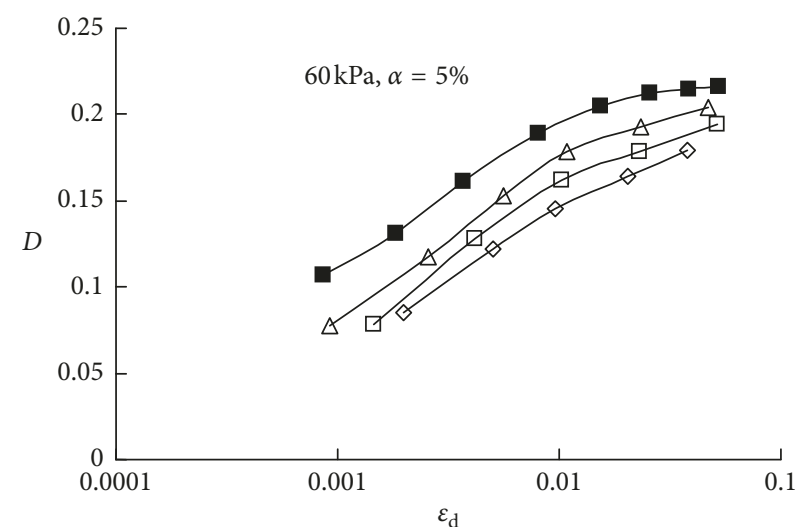

$$
\begin{array}{ll}
\neg \beta=2 \% & \triangle \beta=4 \% \\
\square \beta=3 \% & \rightarrow-\beta=0 \%
\end{array}
$$

(a)

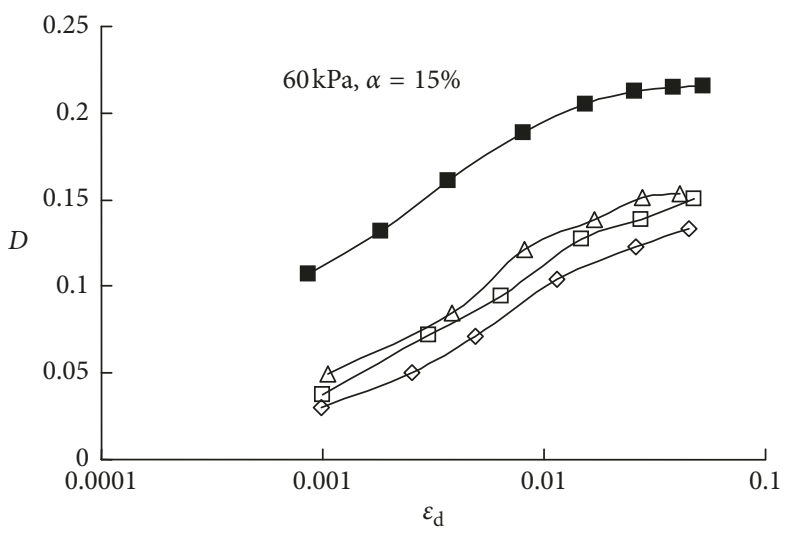

$\diamond \beta=2 \%$

$\square \beta=3 \%$ $\triangle \beta=4 \%$

$-\beta=0 \%$

(b)

FIGURE 13: Relationship between the damping ratio and dynamic strain of LCES and clay at different beads content. 


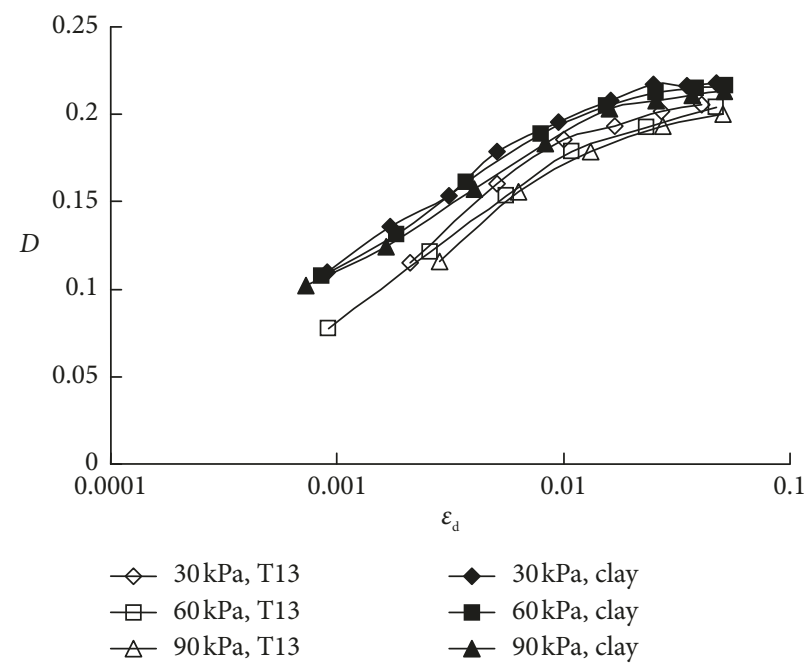

FIGURE 14: Relationship between the damping ratio and dynamic strain of LCES and clay under different confining pressures.

(2) The compressive strain of LCES gradually increased with the increase of load cycles. The strain growth rate decreased with the increase of load cycles. The dynamic strain leveled off, which was consistent with the rule of the hyperbola model.

(3) The dynamic secant elastic modulus of LCES decreased with the increase of dynamic strain, which was represented by strain softening and exhibited a good hyperbolic relationship. The dynamic modulus of clay decreased rapidly, but that of LCES decreased relatively slower. In addition, the dynamic modulus increased with the increase of confining pressure.

(4) The damping ratio of LCES and clay increased with the increase of dynamic strain. The damping ratio of LCES was lower than that of clay. It decreased significantly with the increase of cement content, increased with the increase of EPS beads content, and decreased slightly with the increase of confining pressure.

\section{Data Availability}

The data used to support the findings of this study are available from the corresponding author upon request.

\section{Conflicts of Interest}

The authors declare that they have no conflicts of interest.

\section{Acknowledgments}

This study was supported by the National Foundation of China under Grant Nos. 51609093 and 51869001, the Science Foundation of Jiangsu Education Ministry under Grant No. 16KJB560002, China Postdoctoral Research Funds under Grant No. 2017M611675 for 168401, and Jiangsu Planned Projects for Postdoctoral Research Funds under Grant No.
$1601007 \mathrm{~A}$. These supports are gratefully acknowledged. The assistance from Yifei Sun in improving the English writing of this study is appreciated.

\section{References}

[1] Y. Kikuchi, T. Nagatome, T. A. Mizutani, and H. Yoshino, "The effect of air foam inclusion on the permeability and absorption properties of light weight soil," Soils and Foundations, vol. 51, no. 1, pp. 151-165, 2011.

[2] H. Gao, Y. Hu, Z. Wang, C. Wang, and G. Chen, "Shaking table tests on the seismic performance of a flexible wall retaining EPS composite soil," Bulletin of Earthquake Engineering, vol. 15, no. 12, pp. 5481-5510, 2017.

[3] K. Nagase and H. Kobayashi, "Development of a lightweight soil with styrofoam," Soil and Foundations, vol. 48, no. 6, pp. 13-15, 2000.

[4] K. Tsuchida and H. Tougi, "Application of light-weight soil mixture made from clay and construction soil in coastal engineering," Japan Civil Engineering Society, vol. 20, no. 3, pp. 13-23, 2000.

[5] M. Li, W. Zhu, D. Ma, and F. Ji, "Construction technology and application in-situ of expanded polystyrene treated lightweight soil," Chinese Journal of Geotechnical Engineering, vol. 28, no. 4, pp. 533-536, 2006, in Chinese.

[6] H. Liu, "Technological innovation methods and practices in geotechnical engineering," Chinese Journal of Geotechnical Engineering, vol. 35, no. 1, pp. 34-58, 2013.

[7] M. Li, K. Wen, L. Li, and A. Tian, "Mechanical properties of expanded polystyrene beads stabilized lightweight soil," Geomechanics and Engineering, vol. 13, no. 3, pp. 459-474, 2017.

[8] T. Hou, "Influence of expanded polystyrene size on deformation characteristics of light weight soil," Journal of Central South University, vol. 19, no. 11, pp. 3320-3328, 2012.

[9] T. Hou, "Model for compaction density and engineering properties of light weight soil," Chinese Journal of Geotechnical Engineering, vol. 36, no. 11, pp. 2127-2135, 2014, in Chinese.

[10] H. Gao, R. Chen, F. Tong, G. Chen, and X. Cai, "Dynamic modulus and damping ratio of EPS bead composite soil under 
complex stress conditions," Journal of Disaster Prevention and Mitigation Engineering, vol. 35, no. 2, pp. 166-198, 2015.

[11] H. Gao, J. Liu, and H. Liu, "Geotechnical properties of EPS composite soil," International Journal of Geotechnical Engineering, vol. 5, no. 1, pp. 69-77, 2011.

[12] X. Cai, H. Gao, H. Zhao, G. Chen, and R. Chen, "Dynamic characteristics of EPS beads composite lightweight soil under railway loading," Journal of Disaster Prevention and Mitigation Engineering, vol. 35, no. 5, pp. 651-658, 2015.

[13] R. J. Bathurst, S. Zarnani, and A. Gaskinc, "Shaking table testing of geofoam seismic buffers," Soil Dynamics and Earthquake Engineering, vol. 27, no. 4, pp. 324-332, 2007.

[14] A. C. Trandair, S. F. Bartlett, and B. N. Lingwall, "Behavior of EPS geofoam in stress-controlled cyclic uniaxial tests," Geotextiles and Geomembranes, vol. 28, no. 6, pp. 514-524, 2010.

[15] J. Wang, X. Zhou, S. Wang, and J. Liu, "Study on energy dissipation measures of open cut tunnel under rockfall impact," Journal of Highway Communication Technology, vol. 32, no. 9, pp. 103-108, 2015.

[16] B. M. Das and Z. Luo, "Principles of soil dynamics," in Soil Dynamics and Earthquake Engineering, vol. 13, Cengage Learning, Boston, MA, USA, 3rd edition, 2017.

[17] C. Yan, X. Xu, and L. Huang, "Identifying the impact factors of the dynamic strength of mudded intercalations during cyclic loading," Advances in Civil Engineering, vol. 2018, Article ID 5805294, 9 pages, 2018.

[18] M. H. Maher, K. S. Ro, and J. P. Welsh, "High strain dynamic modulus and damping of chemically grouted sand," Soil Dynamics and Earthquake Engineering, vol. 13, no. 2, pp. 131-138, 1994.

[19] H. Gao, C. Bu, Z. Wang, Y. Shen, and G. Chen, "Dynamic characteristics of expanded polystyrene composite soil under traffic loadings considering initial consolidation state," Soil Dynamics and Earthquake Engineering, vol. 102, pp. 86-98, 2017. 


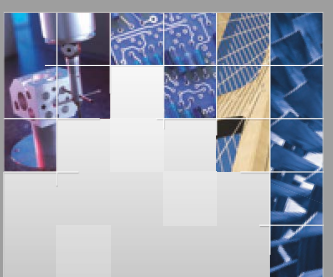

\section{Enfincering}
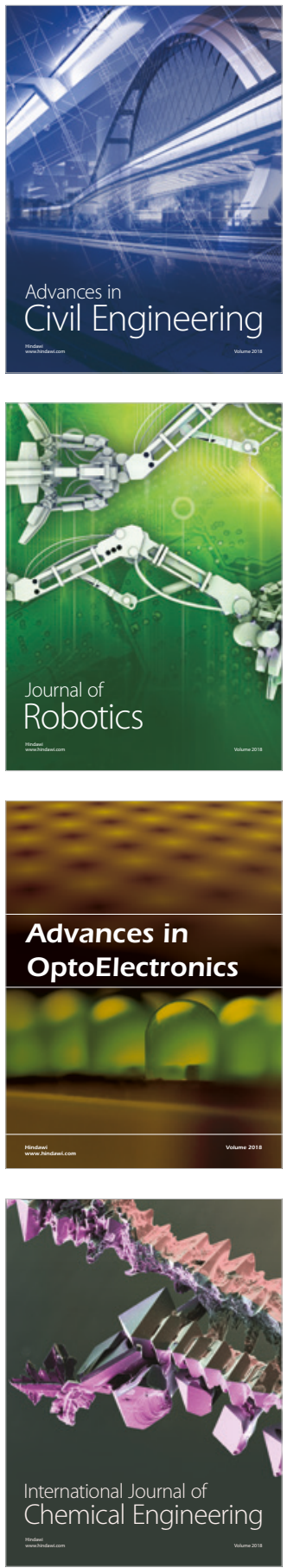

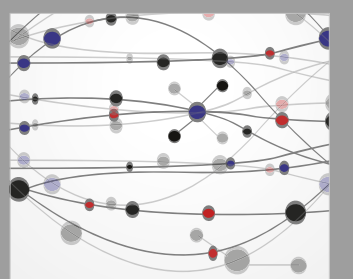

\section{Rotating \\ Machinery}

The Scientific World Journal

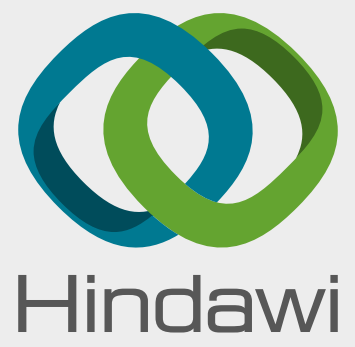

Submit your manuscripts at

www.hindawi.com
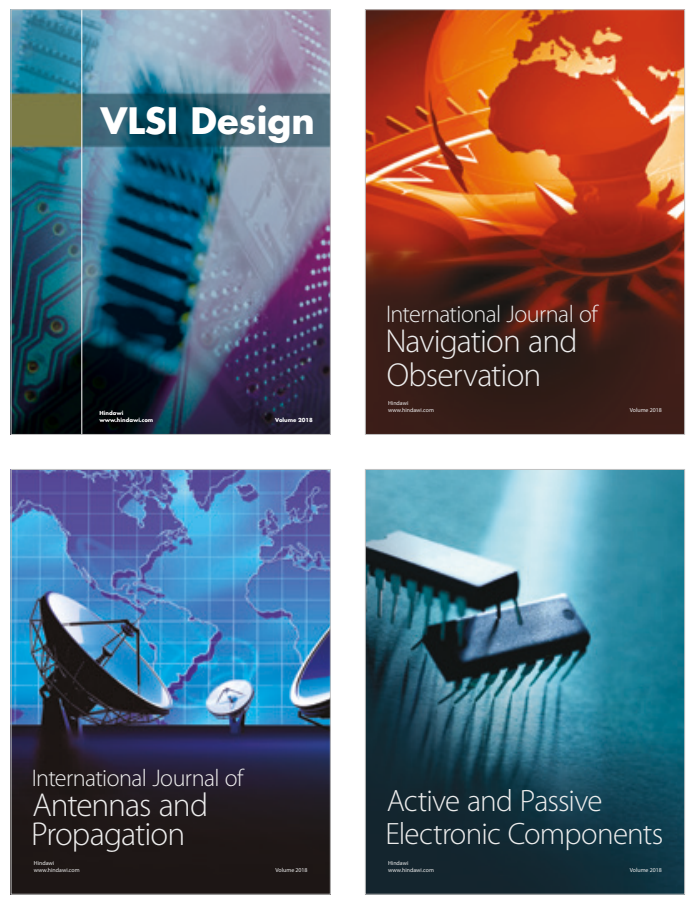
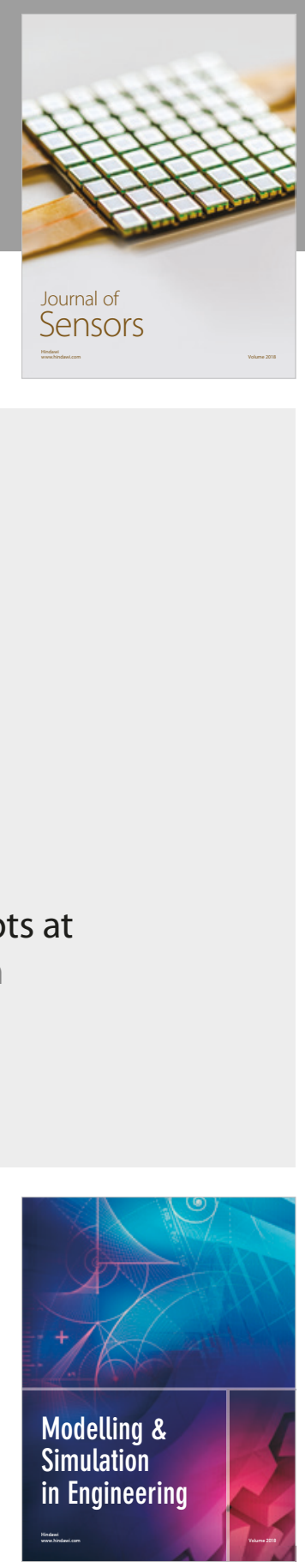

\section{Advances \\ Multimedia}
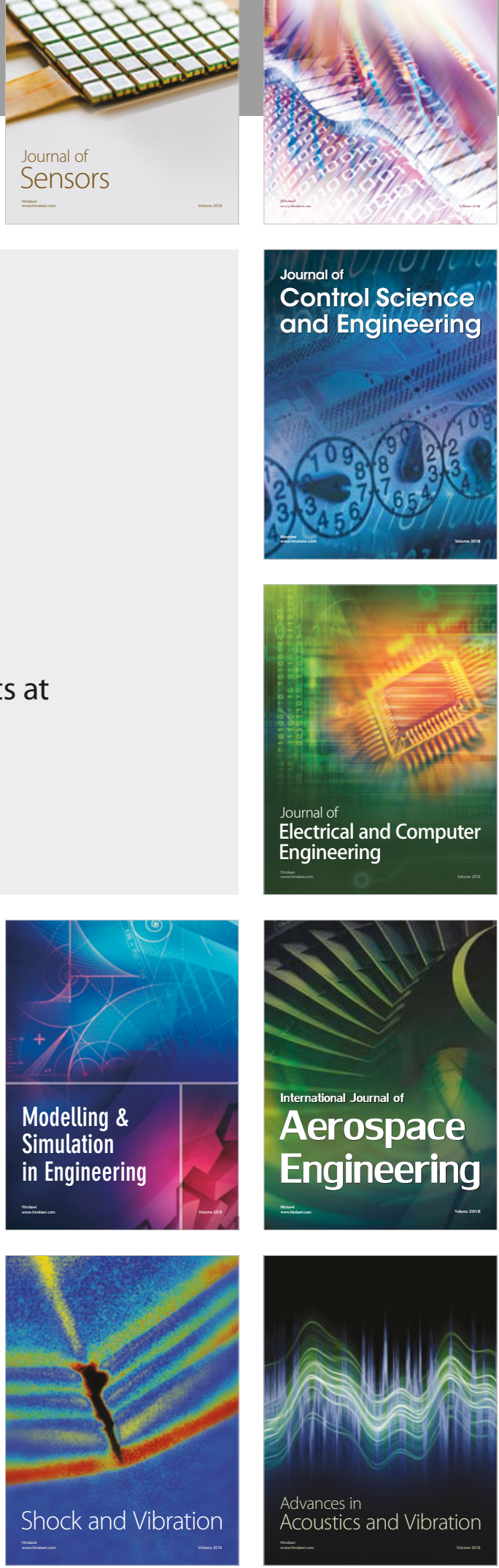